\title{
POWER INDICES AND THE MEASUREMENT OF CONTROL IN CORPORATE STRUCTURES
}

\author{
YVES CRAMA \\ QuantOM, HEC Management School, University of Liège, \\ 4000 Liège, Belgium \\ Yves.Crama@ulg.ac.be \\ LUC LERUTH \\ IMF, Central AFRITAC, \\ Washington DC 20431, USA \\ lleruth@imf.org \\ Received (Day Month Year) \\ Revised (Day Month Year)
}

\begin{abstract}
This paper proposes a brief review of the use of power indices in the corporate governance literature. Without losing sight of the field of application, it places the emphasis on the game-theoretic aspects of this research and on the issues that arise in this framework.

Keywords: Simple games; voting; power index; corporate governance; ownership structure.

Subject Classification: C71 Cooperative Games, G3 Corporate Finance and Governance.
\end{abstract}

\section{Introduction}

Power indices reflect the importance of the players in a cooperative game. In the context of simple games, or voting games, they have been first introduced in pioneering papers by Penrose [1946], Shapley and Shubik [1954], Banzhaf [1965], and subsequently investigated in a huge number of papers spanning across many scientific disciplines, from political science and economics to mathematics and computer science. Closely related concepts have been investigated in electrical engineering, in reliability analysis, in database theory, and so forth. We refer to Crama and Hammer [2011] for numerous references in the broader context of Boolean theory.

In practice, however, the analysis of voting rules by means of power indices seems to be mostly restricted to two types of real-world applications: the measurement of the (relative) power of members of political assemblies, on one hand, and of shareholders of corporations, on the other hand. These two paradigmatic examples were already identified by Shapley and Shubik [1954], and have been the subject of much subsequent work. 
Applications in political science are usually well-known from game-theoreticians, and various aspects are discussed in excellent monographs; see, for instance, Felsenthal and Machover [1998], Bilbao [2000], Brams [2004]. In this paper, we focus on the use of power indices to model control relationships in corporate structures. We place the emphasis on the game-theoretic aspects of this research, and we devote little space to economic uses or interpretations. Also, we do not claim to be exhaustive in our literature review, but we try to cite the most relevant and illustrative references.

\section{Corporate Finance: Ownership vs. Control}

Corporate governance is a topic of great importance in financial economics. It is surveyed for instance in papers by Shleifer and Vishny [1997], or Becht, Bolton, and Röell [2003]. Many of the questions addressed in the corporate governance literature revolve around ownership concentration patterns, voting power, agency conflicts between owners and managers, the rationale behind takeovers, the influence of all these factors on the value and on the economic performance of the firm, and so forth. A fundamental observation is that significant concentrations of shares are necessary to ensure control of firms, and are frequently observed in practice, in contrast with the diversification of investment recommended by classical portfolio theory.

In all such studies, ownership and control of a firm are two concepts that need to be carefully distinguished. Simply stated, ownership refers to the property of the shares of the firm. It determines, in particular, the distribution of cash-flow rights, such as dividends. Control, on the other hand, reflects the ability to influence the strategic decisions of the firm. The extent of control that a shareholder can exert over a specific firm is clearly related to the fraction of shares that it owns, but also depends on other factors such as the dispersion of shares, so that the exact relation is not easily modeled. Actually, there does not seem to be a general agreement among economists regarding the most appropriate model to be used for the measurement of control: the notion of "control" and of its measurement is indeed a complex one. Let us provide a few illustrations of this assertion.

- One of the definitions of a controlling shareholder in LaPorta et al. [1999] relies on the concept of a cutoff point, that is, a critical percentage $c$ of shares such that the largest shareholder is deemed to have effective control over the firm's decisions if it owns more than $c \%$ of its shares. Similar cutoff points have been adopted by several authors (going back to Berle and Means [1932]), but the actual percentage used in different studies may vary from $c=10 \%$ to $c=40 \%$.

Note that this approach does not really provide a measure of control, but only a notion of controlling entity. It is also easy to see that it may be very inappropriate in some contexts, for instance, when two large shareholders both own more than $c$ percent of the shares. 
- Pyramidal shareholding structures are frequently observed in Asian and European markets (see, e.g., LaPorta et al. [1999], Claessens, Djankov and Lang [2000], Gorton and Schmid [2000], Claessens, Djankov, Fan and Lang [2002]). Claessens et al. [2000,2002] rely on a definition of control which only takes voting rights into account. In short, they consider that, along a chain of voting rights from a parent corporation $A$ to firm $B$, to firm $C, \ldots$, to firm $T$, the smallest shareholding in the chain defines the extent of the control of $A$ over $T$. Control rights along different chains are assumed to be purely additive. Again, small examples show that this measure of control cannot be fully satisfactory (see Crama and Leruth [2007] or Figure 1 hereunder).

- Eurostat is the statistical office of the European Union. In its recommendations for the setup of a multinational business register, Eurostat [2010] states guidelines for the identification of controlling entities, and clearly identifies some shortcomings of the classical concepts ${ }^{\mathrm{a}}$. We quote a few passages from Chapter 21 of this publication:

(...) control may be exercised in different ways. The acquisition of an absolute majority $(50 \%+1)$ of shareholdings with voting rights is the main instrument used to take control over a legal unit and in the absence of other information it is generally used as a proxy to control. On the other hand, the absolute majority of ownership (...) is not always necessary or a sufficient condition to have control. (...)

In order to control more than half the shareholders voting power, an institutional unit need not own any of the voting shares itself. A corporation $C$ could be a subsidiary of another corporation $B$ in which a third corporation $A$ owns a majority of the voting shares. (...)

Effective minority control means having effective control of a unit without holding the majority of voting stock. It does not include indirect control via a majority-controlled subsidiary. The most common case is a minority but large shareholder and a very large number of dispersed small shareholders, none of whom hold a significant share of the capital. (...) Effective minority control is, in general, difficult to prove in practice and a shareholding between 10 and 50 percent is generally regarded as influence, not control.

Eurostat [2010] also provides the small numerical example depicted in Figure 1: here, "X owns indirectly $(60 \% * 30 \%)+(60 \% * 30 \%)=36 \%$ of $C$," but " $X$ controls $C$ through its two subsidiaries $A$ and $B$ by combining their voting rights in the meeting of $C$. On the other hand, $Y$ owns $(40 \%$ * $30 \%)+(100 \% * 40 \%)=52 \%$ of $C$, but has no power to control it, since

\footnotetext{
a The comments in Eurostat [2010] are especially interesting because they arise in a non-academic application, where we may want to compute the amount of control detained by various entities, or to identify the ultimate shareholders of a given firm, or to determine corporate groups, based on large amounts of numerical data. This turns out to raise several challenges, as we explain further down.
} 
the voting rights (...) amount only to 40\%." This example clearly illustrates the distinction between ownership and control.

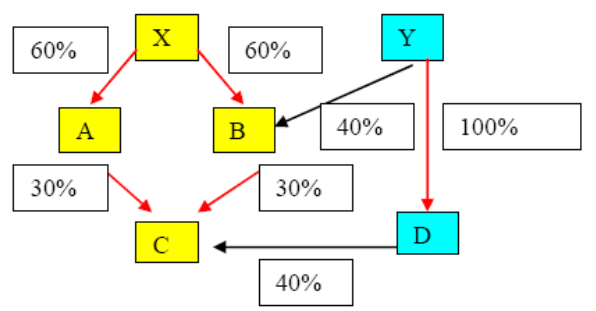

Fig. 1. A shareholding structure from Eurostat [2010].

- Still other authors rely on concentration measures related to the Herfindahl index (as in Gorton and Schmid [2000], for instance), or on measures of integrated ownership inspired from input-output methodology (see, e.g., Ellerman [1991], Chapelle and Szafarz [2005]).

\section{Power Indices}

In view of the above considerations, and especially in view of the shortcomings of analyses based on "cutoff points", several authors have advocated the use of game-theoretical power indices in order to measure control in corporate groups. In such models, shareholders are interpreted as players in a simple (or voting) game. Recall (Shapley [1962]) that a simple game is a set function $v: 2^{N} \rightarrow\{0,1\}$, where $N=\{1,2, \ldots, n\}$ is a finite set of players and $2^{N}$ is the power set of $N$, such that (i) $v(\emptyset)=0$;

(ii) if $S \subseteq T$, then $v(S) \leq v(T)$.

Equivalently, a simple game can be modeled as a monotonically nondecreasing Boolean function $f_{v}:\{0,1\}^{n} \rightarrow\{0,1\}$. Here, the variables of $f_{v}$ are in 1-to- 1 correspondence with the players of the game (variable $x_{i}$ takes value 1 exactly when player $i$ votes "Yes") and the value of the function reflects the outcome of the vote for each vector of individual votes ${ }^{\mathrm{b}}$. More precisely, for all $X=\left(x_{1}, x_{2}, \ldots, x_{n}\right) \in$ $\{0,1\}^{n}$,

$$
\begin{aligned}
f_{v}(X) & =1 \text { if } v\left(\left\{i: x_{i}=1\right\}\right)=1 \\
& =0 \text { otherwise, }
\end{aligned}
$$

\footnotetext{
${ }^{\mathrm{b}}$ The multilinear extension of a game introduced by Owen [1972] is based on a particular representation of the Boolean function $f_{v}$, called its (pseudo-Boolean) polynomial expression in Crama and Hammer [2011].
} 
where $\left\{i: x_{i}=1\right\}$ is the index set of the players who vote "Yes". This equivalent model allows us, in particular, to speak of the composition of $k$ simple games $g_{1}, g_{2}, \ldots, g_{k}$ by another game $g$ : this is just the compound game

$$
f=g\left(g_{1}, g_{2}, \ldots, g_{k}\right) \text {. }
$$

In (1), the players are viewed as playing first the subgames $g_{1}, g_{2}, \ldots, g_{k}$; next, in a second stage, the outcomes of these subgames are combined by means of the aggregating game $g$ to produce the final outcome of the compound game $f$ (see Shapley [1962]).

In the simplest situation, the game $v$ associated with a firm is the weighted majority game played by its shareholders, where shareholder $i \in N$ carries a weight $w_{i}$ corresponding to its voting rights, and a decision requires a simple majority of the votes: for all $S \subseteq N$,

$$
v(S)=1 \Longleftrightarrow \sum_{i \in S} w_{i}>\frac{1}{2} \sum_{i \in N} w_{i} .
$$

A main theme of study in game theory is the computation of the amount of power held by each player, and several indices have been proposed for this purpose. In the context of corporate networks, power indices are expected to reflect the influence of each shareholder (be it a firm or an individual investor) on the outcome of a vote, that is, the relative capacity of each shareholder to impose its will on the management of the target company.

We briefly define here the two main power indices, and we refer to Owen [1995], Felsenthal and Machover [1998], or Bilbao [2000] for details. The Shapley-Shubik (SS) index of player of player $j \in N$ in game $v$ is defined as

$$
S S_{v}(j)=\sum_{T \subseteq N \backslash j} \frac{|T| !(n-|T|-1) !}{n !}[v(T \cup j)-v(T)] .
$$

The (non-normalized) Banzhaf index (sometimes called Penrose-Banzhaf, or PB-index) of player $j \in N$ is

$$
P B_{v}(j)=\frac{1}{2^{n-1}} \cdot \sum_{T \subseteq N \backslash j}[v(T \cup j)-v(T)] .
$$

Both indices can be interpreted in probabilistic terms: the index of a player is the probability that the player is critical, or pivotal (that is, influences the outcome of the vote), over different distributions of voting patterns.

\subsection{A brief literature review}

The relevance of power indices for the measurement of shareholders' importance was already pointed out by Shapley and Shubik [1954] in their seminal paper, and taken up again by Shapley in 1961 (see Milnor and Shapley [1978]). 
In his analysis of British corporations, Florence [1961] briefly refers to probabilistic voting models and to the work of Penrose [1946]. But it seems that the topic was only really picked up again in the early 80 's.

Following earlier work by Amihud and Barnea [1974], Gambarelli [1982] proposes a portfolio selection model that takes into account the value of controlling blocks of shares, as measured through Shapley-Shubik indices. A basic question in this context concerns the impact of trading, that is, buying or selling shares, on the level of control. This issue is examined in several related papers by Arcaini and Gambarelli [1986], Gambarelli [1983,1994,1996].

Cubbin and Leech [1983] are interested in analyzing the concentration of shares in relation with control. They underline the weaknesses of the approaches based on "cutoff" values, such as those mentioned in Section 2 (especially, their ill-defined and ad hoc character). In order to measure control, these authors rely instead on a model that is essentially similar to the Penrose-Banzhaf one (they cite Florence [1961] and Penrose [1946], but do not refer to the game-theoretic setting). In such models, voting power is usually found to be more concentrated than voting rights (shares). The connections with game theory and with the Shapley-Shubik or Penrose-Banzhaf power indices are made explicit in a subsequent series of papers by Leech [1987a, 1987b, 1988].

The use of power indices in corporate finance has been further explored, among others, by Rydqvist [1987], Pohjola [1988], Leech and Leahy [1991], Gambarelli and Owen [1994], Zingales [1994], Zwiebel [1995], Khatri, Leruth and Piesse [2002], Leech [2002, 2003], Leech and Manjòn [2003], Crama, Leruth, Renneboog and Urbain [2003], Nenova [2003], Gambarelli and Pesce [2004], Nicodano and Sembenelli [2004], Crama and Leruth [2007], Levy [2009, 2011], Edwards, Eggert and Weichenrieder [2009], Edwards and Weichenrieder [2009], Aminadav et al. [2011], and so on. We return to several of these papers later on.

\section{Research Questions}

Keeping in line with the objectives of the special issue, we now raise several questions that directly relate to the game-theoretic framework described in previous sections.

We start in Section 4.1 with two points regarding the relevance of power indices for the analysis of control in corporate structures.

Next, we observe that much of the early literature on applications of power indices in corporate finance focused on the analysis of the direct shareholders of a single firm. In this case, as explained in Section 3, the voting game played by the shareholders is a weighted majority game.

Real-world shareholding structures, however, often display several features that are absent from this simple basic model, and which actually distinguish corporate governance applications from more traditional applications arising in political science. In particular, shareholding structures frequently involve several layers of ownership, which form subsets of very large financial networks (such as whole na- 
tional economies or industrial sectors), possibly involving cyclic relations, and for which substantial amounts of data may be missing. The importance of these features and their impact on the measurement of control have been stressed in many publications, such as Gorton and Schmid [2000], Crama and Leruth [2007], Edwards, Eggert and Weichenrieder [2009], Edwards and Weichenrieder [2009], and so on. They are discussed in Sections 4.2 to 4.5 .

\subsection{Relevance of the indices}

Power indices are a priori measures of the voting power, or control, held by a shareholder. For a given design of the governance structure of the firm, they measure the likelihood that a player may be able to exert an influence on the decisions of the firm, without prior assumptions about the tactical behavior of the shareholders. They claim neither to explain nor to predict how the votes are actually cast in shareholders meetings, nor what coalitions may form in practice, and they do not rely on voting records or other empirical data. It would be interesting, however, to explore the links between a priori and a posteriori expressions of voting power in corporations. (See also Bebchuk and Hart [2001] or Edelman and Thomas [2005] for a different stream of research, influenced by legal directives and court decisions.)

Moreover, there has been little discussion in the literature as to what power index is better suited for the analysis of corporate structures. Most researchers pick either the Shapley-Shubik or the Penrose-Banzhaf index without further justification, or based on alleged differences between the bargaining models on which they rest, or because of the (perceived) difficulty of their respective computations. An exception is Leech [2002], who stated a number of reasonable criteria that should be satisfied by power indices in the context of corporate control, and tested them on a sample of British corporations. His experiments indicate that the Banzhaf index is better suited than the Shapley-Shubik index in this context. More generally, Felsenthal and Machover [1998, 2005] underline the shortcomings of the Shapley-Shubik index when this index is interpreted as a measure of "power as influence" (I-power), as opposed to "power as a prize" (P-power). They convincingly argue that the concept of P-power, which relies on a "division of spoils" and defines a value in the sense of transferable utility cooperative game theory, is not adapted to the analysis of political structures, and that a non-normalized Penrose-Banzhaf, or a similar type of I-power index, is much better suited in this context. It seems that many (though not all) of their comments carry over to the corporate context. Nevertheless, many analysts of corporate structures have initially adopted the SS index to model the "division of private benefits" implied by voting rights; see, for instance, Gambarelli [1982], Rydqvist [1987], Zwiebel [1995]. We believe that these issues deserve further consideration. 


\subsection{Float and incomplete structures}

A fundamental assumption of game-theoretic models of corporate governance is that control rights are somehow derived from voting rights, and that voting rights are directly related to ownership. In spite of the apparent simplicity of this assumption, real-world data concerning voting rights is not always readily available. Numerous obstacles of various natures may crop up here (these issues are discussed in many academic papers; see, for instance, Zingales [1994], Gorton and Schmid [2000], or Edwards and Weichenrieder [2009]; see also Eurostat [2010] for practical attempts to circumvent a number of difficulties):

- Different types of shares may either carry one vote per share, or multiple voting rights, or no voting rights at all; some shareholders (for instance, large institutional shareholders, such as banks) may carry a significant amount of proxy-voting rights on behalf of other shareholders.

- For any given firm, only a few main shareholders are usually known. The transparency requirements enacted in most countries frequently require that shareholders owning more than $3 \%$, or $5 \%$ of the shares be explicitly identified. This leaves out, however, a very large number of small holders. Moreover, even this regulatory information is not always included in easily accessible databases.

- When dealing with large databases including many layers of complex ownership structures, such as those associated with national economies or with specific industrial sectors, it may be hard to decide to what depth the relevant information should be collected: the "ultimate shareholder" of a corporation may be located on a different continent and be active in a different industrial sector.

In practice, these (and other) features make it quite hard, or even impossible to collect complete information about ownership networks.

From a theoretical point of view, a most interesting question concerns the choice of an appropriate model for modeling the float, that is, the collection of small, unidentified shareholders. Although each such shareholder may be powerless by itself, the existence of the float may influence the amount of control held by the main holders, as observed for instance by Cubbin and Leech [1983]. ${ }^{\mathrm{c}}$

Several researchers have discussed this issue. A possible model for the float is provided by oceanic games, that is, weighted majority games involving a finite set of major players, as well as a continuum of infinitesimal minor players. Shapiro and Shapley [1978], Milnor and Shapley [1978], Dubey and Shapley [1979] investigated the theoretical properties of power indices in oceanic games. They showed that both the SS index and the PB index behave nicely in such limit games, and converge to values that only depend on the weights of the major players.

${ }^{\mathrm{c}}$ Rydqvist [1987] and Zingales [1994] focus on the amount of power held by the block of small shareholders. Some authors, like Aminadav et al. [2011], disregard the float altogether. 
In the context of corporate governance, computational implementations of related concepts have been proposed, among others, by Cubbin and Leech [1983], and Leech $[1988,2002,2003]$. These authors considered two extreme cases: The first one is that of an oceanic game, and corresponds to a highly dispersed float. In this case, the results of Shapley et al. can be used to compute the SS and PB indices of the major players. The second case assumes that the float is concentrated, so that each of the unidentified shareholders owns the same fraction of shares as the smallest identified shareholder. The minor players can be explicitly handled by enumeration algorithms if their number is not too large; otherwise, their combined vote can be viewed as a normally distributed random variable ${ }^{\mathrm{d}}$ and used to approximate power indices by numerical integration, as in Owen [1972,1975], Leech [1988,2002,2003], Pohjola [1988], or in a Monte Carlo algorithm for the computation of the power indices, as in Crama and Leruth [2007].

The previous approaches provide different ways of modeling the float in weighted majority games; it would be interesting to validate them in a variety of applications (see Leech [2002] for investigations along these lines; see also Edwards and Weichenrieder [2009], Levy [2011]). More importantly, perhaps, the impact of the float in general games associated with multilevel pyramidal structures appears to have been disregarded so far, and needs to be appraised both from the theoretical and from the computational points of view. It is not clear whether the analysis in Shapiro and Shapley [1978] or Dubey and Shapley [1979] can be extended in the general case.

\subsection{Pyramidal structures}

As mentioned in Section 2, corporate governance structures frequently feature multiple levels of ownership, cross-holdings, and even longer cycles that complexify the relation between ownership and control. This point has been stressed by many researchers; see, e.g., La Porta et al. [1999], Claessens, Djankov and Lang [2000], Gorton and Schmid [2000], Claessens, Djankov, Fan and Lang [2002], Chapelle and Szafarz [2005], Almeida and Wolfenzon [2006], Edwards, Eggert and Weichenrieder [2009], Edwards and Weichenrieder [2009], and so forth.

Any complex ownership structure can be represented by a directed graph $G$, as illustrated by Figure 1, with cross-holdings corresponding to cycles in the graph. A formal graph-theoretic model is defined by Crama and Leruth [2007]; we do not repeat it here and rely instead on an intuitive description (see Bang-Jensen and Gutin [2000] for terminology).

In the absence of cycles, a simple game $v_{j}$ can be associated with any firm $j$ and any set $N$ of indirect shareholders. To define this game $v_{j}$, consider the set $M$ of all firms located on directed paths from the set $N$ of shareholders to $j$, and consider the subgraph of $G$ induced by $M$, say $G[M]$. Let us assume for simplicity that there

$\mathrm{d}$ Zwiebel [1995] assumes that the vote of the float is uniformly distributed. 
are no arcs between the shareholders in $N$. When the indirect shareholders in $N$ vote "Yes", their vote propagates down to $j$ through a sequence of intermediate (weighted majority) games (possibly, with float) $g_{i}, i \in M \backslash N$, played at the nodes of $G[M]$. This voting procedure defines the simple game $v_{j}$ on the player-set $N$; see Crama and Leruth [2007] for details. Note that the procedure actually associates a game $v_{i}$ on the player-set $N$ with each firm $i \in M$. Gambarelli and Owen [1994] provide an alternative and slightly more general description of this collection of games, which they call the consistent reduction of the original structure on $G[M]$.

Example. Consider again Figure 1, let $j$ be firm $C$ and let $N=\{X, D\}$. Then, $G[M]$ is the subgraph obtained by deleting $Y$ from Figure 1 . If $X$ votes "Yes" and $D$ votes "No", then the vote of $X$ propagates first to $A$ and $B$ (independent of the vote of the float), then to $C$ by the majority procedure involving $A, B$, and $D$.

The game $v_{j}$ is well-defined, up to the definition of the behavior of the float. It is nothing but a compound game obtained by composition of the weighted majority games $g_{i}$ associated with the intermediate nodes $i \in V \backslash N$, in the sense of Equation 1.

When dealing with large databases, as in Crama et al. [2003], Crama and Leruth [2007], Aminadav et al. [2011], questions of algorithmic efficiency become of paramount importance. Much literature has been devoted to the computation of power indices of simple games and of special classes of games, such as weighted majority games; see, e.g., Bilbao [2000], Matsui and Matsui [2000], Klinz and Woeginger [2005], Aziz et al. [2009], Bachrach et al. [2010], Crama and Hammer [2011]. Various methodologies have been proposed, based on dynamic programming, generating functions, Monte-Carlo simulation, multilinear extensions, and so on. The development and analysis of algorithms specifically tailored for the complex pyramidal structures encountered in shareholding networks, however, constitutes an interesting challenge.

Note that, contrary to our description of the game $v_{j}$, the classical definition of compound games assumes that the sets of players involved in subgames are pairwise disjoint (that is, the functions $g_{1}, g_{2}, \ldots, g_{k}$ in Equation 1 depend on disjoint subsets of variables). Under this assumption, Owen [1978] proved that the Penrose-Banzhaf index of a compound game can be recursively computed based on the following principle: the PB-index of a voter $\ell$ in a two-tiered compound game is equal to (the PB-index of $\ell$ in the first-tier game $g_{i}$ that he participates in) $\times$ (the PB-index of $g_{i}$ in the second-tier game) (see also Dubey, Einy and Haimanko [2005]).

This recursive rule, however, does not apply to the Shapley-Shubik index, and does not even apply to the PB-index when the subgames $g_{i}$ depend on non-disjoint subsets of players, as observed by Crama and Leruth [2007] for the case of a simple pyramidal structure.

As a consequence, computing the power indices of players in pyramidal struc- 
tures turns out to be nontrivial. Based on this observation, Edwards, Eggert and Weichenrieder [2009], Edwards and Weichenrieder [2009] decide to use the product of SS-indices at each tier of a pyramid as an approximation of the true SS-index. The quality of this approximation is not known.

Gambarelli and Owen [1994] propose to compute the multilinear extension of the game $v_{j}$, and to use this multilinear extension in order to calculate the power indices, as explained in Owen [1972,1978]. This approach, however, appears to be computationally prohibitive and may be extremely difficult to apply to large networks involving several hundreds or thousands of firms.

Crama and Leruth [2007] rely instead on a Monte-Carlo approach to compute PB-indices in large pyramidal networks ${ }^{\mathrm{e}}$. This approach is applicable to general simple games, and can also be used to obtain the SS-indices. In its principle, it goes back to Mann and Shapley [1960]. Efficient variants and theoretical complexity analyses for general games have been proposed by Bachrach et al. [2010] (see also Karp, Luby and Madras [1989]).

Finally, the reader should note that, in our definition of the game $v_{j}$ at the beginning of this section, we have assumed that the set of players $N$ was given. In practice, the ultimate controlling shareholders of a corporation may not be known in advance: in fact, the objective of the analysis is frequently to identify these ultimate shareholders; see La Porta et al. [1999] for a discussion. Crama and Leruth [2007] and Aminadav et al. [2011] rely in various ways on the computation of power indices to sequentially trim down the ownership structures, until a collection of ultimate shareholders emerges. More work is needed to understand the properties and the computational complexity of such heuristic procedures.

\subsection{Cyclic structures}

When the graph associated with the shareholding network contains cycles, the game $v_{j}$ described in Section 4.3 is no longer well-defined. This poses a most serious problem for the use of power indices in corporate governance studies ${ }^{f}$. This issue has been explicitly tackled by a few researchers.

Gambarelli and Owen [1994] provide a nice theoretical framework and an analysis which essentially imply that a notion of a consistent reduction $v_{j}$ can still be associated with a firm $j$ and a set $N$ of shareholders, even in the presence of cyclic holdings. A main difficulty with their approach (apart from its computational complexity, as already mentioned in the previous section) is that it does not necessarily yield a unique consistent reduction in the cyclic case. This residual ambiguity may be inherent to cyclic shareholding structures, as it may simply reflect the instability of the governance structure in this case.

eThe formula given by Crama and Leruth [2007] for the estimator of the PB-index is erroneous, but is easily corrected.

${ }^{\mathrm{f}}$ Approaches that do not rely on a game-theoretic framework have been proposed to take ownership cycles into account; see, e.g., the input-output model in Chapelle and Szafarz [2005]. 
In their Monte-Carlo simulation-based algorithm, Crama and Leruth [2007] handle cycles by generating sequences of votes that reflect the possible behavior of players in a cyclic network: at every moment in time, each firm observes the position adopted by its direct shareholders, then modifies its vote accordingly. This adjustment process repeats until a stable pattern of votes emerges, or is randomly terminated. A formal Markov chain model of this process is investigated by Wang [2009] and Crama, Leruth and Wang [2011], who show that, under certain circumstances, the sequence of iterations converges to a stationary distribution which can be meaningfully sampled.

More research is needed in order to understand the role of cycles in ownership structures and, if possible, to include them meaningfully in game-theoretic models. It may prove interesting, in particular, to investigate the relations between such models and the literature on command games and on influence in social networks; see, e.g., Hu and Shapley [2003], and the survey by Grabisch and Rudinowska [2010].

\subsection{Additional topics}

We conclude this paper with a brief mention of two additional topics for future research.

Dynamic games. Many authors have underlined the usefulness of power indices for the investigation of takeovers. Roughly speaking, the trading price of a block of shares is frequently higher than what would be predicted from the price of individual shares. In the corporate governance literature this premium is usually linked to the existence of private benefits derived from control. Gambarelli [1982, 1983, 1996], Leech [1987b], Zwiebel [1995], Gambarelli and Pesce [2004], Nicodano and Sembenelli [2004], among many others, have looked into such issues, which bring the attention to the evolution of power indices subject to modifications of the underlying games. Becht, Bolton and Röell [2003] point out that: "From a theoretical point of view static measures of concentration are not always satisfactory. (...) Dynamic measures of power based on power indices can address some of these issues." Research along these lines remains scarce.

Other solution concepts. The basic idea underlying much of the literature surveyed in this paper is that the interactions occurring in corporate governance structures can be modeled by simple games. Beside power indices, several solution concepts (kernel, nucleolus, core and its variants) have been introduced for simple games; see, e.g., Bilbao [2000]. To the best of our knowledge, the use of these concepts in corporate governance has not been broadly explored so far, but may deserve further consideration. For instance, Megiddo [1974] points out that the nucleolus of a game reflects strength relations between players, and Montero [2004] argues that the nucleolus can be usefully interpreted as a power index. Concepts of "dominating coalitions" could also be investigated in order to identify the "core shareholders" - an expression sometimes loosely used in the economic literature of a company or group of companies. 


\section{References}

Almeida, H. V. and Wolfenzon, D. [2006] A theory of pyramidal ownership and family business groups, Journal of Finance 61, 2637-2680.

Amihud, Y. and Barnea, A. [1974] Portfolio selection for managerial control, Omega 2, $775-783$.

Aminadav, G., Bachrach, Y., Kosenko, K., Rosenschein, J. S. and Wilf, Y. [2011] Rebuilding the Great Pyramids: A method for identifying control relations in complex ownership structures, Working paper, Available at SSRN: http://ssrn.com/abstract $=1903941$.

Aziz, H., Lachish, O., Paterson, M. and Savani, R. [2009] Power indices in spanning connectivity games, in: Goldberg, A. V. and Zhou, Y., editors, Algorithmic Aspects in Information and Management, AAIM 2009, Lecture Notes in Computer Science 5564, Berlin Heidelberg: Springer-Verlag, pp. 55-67.

Bachrach, Y., Markakis, E., Resnick, E., Procaccia, A. D., Rosenschein, J. S., and Saberi, A. [2010] Approximating power indices: theoretical and empirical analysis, $A u$ tonomous Agents and Multi-Agent Systems 20, 105-122.

Bang-Jensen, J. and Gutin, G. [2000] Digraphs: Theory, Algorithms and Applications, London: Springer-Verlag.

Banzhaf III, J. F. [1965] Weighted voting doesn't work: a mathematical analysis, Rutgers Law Review 19, 317-343.

Bebchuk, L. A. and Hart, O. D. [2001] Takeover bids vs. proxy fights in contests for corporate control, ECGI - Finance Working Paper No. 04/2002; Harvard Law and Economics Discussion Paper No. 336, Available at SSRN: http://ssrn.com/abstract $=290584$.

Becht, M., Bolton, P. and Röell, A. [2003] Corporate governance and control, Chapter 1 in: Constantinides, G. M., Harris, M. and Stulz, R. M., editors, Handbook of the Economics of Finance, Volume 1, Part 1, Corporate Finance, Amsterdam: Elsevier, pp. $1-109$.

Berle, A. and Means, G. [1932] The Modern Corporation and Private Property, New York: MacMillan.

Bilbao, J. M. [2000] Cooperative Games on Combinatorial Structures, Dordrecht: Kluwer Academic Publishers.

Brams, S. J. [2004] Game Theory and Politics, Mineola, NY: Dover Publications.

Chapelle, A. and Szafarz, A. [2005] Controlling firms through the majority voting rule, Physica A 355, 509-529.

Claessens, S., Djankov, S., Fan, J. P. H. and Lang, L. H. P. [2002] Disentangling the incentive and entrenchment effects of large shareholdings, Journal of Finance 57, 2741-2771.

Claessens, S., Djankov, S. and Lang, L. H. P. [2000] The separation of ownership and control in East Asian corporations, Journal of Financial Economics 58, 81-112.

Crama, Y. and Hammer, P. L. [2011] Boolean Functions: Theory, Algorithms, and Applications, New York: Cambridge University Press.

Crama, Y. and Leruth, L. [2007] Control and voting power in corporate networks: Concepts and computational aspects, European Journal of Operational Research 178, 879-893.

Crama, Y., Leruth, L., Renneboog, L. and Urbain, J.-P. [2003] Corporate control concentration measurement and firm performance, in: Batten, J. A. and Fetherston, T. A., editors, Social Responsibility: Corporate Governance Issues, Amsterdam: Elsevier, pp. $123-149$.

Crama, Y., Leruth, L. and Wang S. [2011] A Markov chain model of power indices in 
corporate structures, Working paper (in preparation), University of Liège.

Cubbin, J. and Leech, D. [1983] The effect of shareholding dispersion on the degree of control in British companies: Theory and measurement, The Economic Journal 93, 351-369.

Dubey, P., Einy, E. and Haimanko, O. [2005] Compound voting and the Banzhaf index, Games and Economic Behavior 51, 20-30.

Dubey, P. and Shapley, L. S. [1979] Mathematical properties of the Banzhaf power index, Mathematics of Operations Research 4, 99-131.

Edelman, P.H. and Thomas, R.S. [2005] Corporate voting and the takeover debate, Vanderbilt Law Review 58, 453-498.

Edwards, J.S.S., Eggert, W. and Weichenrieder, A. [2009] Corporate governance and pay for performance: Evidence from Germany, Economics of Governance 10, 1-26.

Edwards, J. S. S. and Weichenrieder, A. J. [2009] Control rights, pyramids, and the measurement of ownership concentration, Journal of Economic Behavior and Organization 72, 489-508.

Ellerman, D. [1991] Cross-ownership of corporations: a new application of input-output theory, Metroeconomica 42, 33-46.

Eurostat [2010] Business Registers: Recommendations Manuel, Eurostat methodologies and Working papers, 2010 Edition, Luxembourg: Publications Office of the European Union, Available in electronic form at DOI 10.2785/39851.

Felsenthal, D. S. and Machover, M. [1998] The Measurement of Voting Power: Theory and Practice, Problems and Paradoxes, Cheltenham, UK: Edward Elgar.

Felsenthal, D. S. and Machover, M. [2005] Voting power measurement: A story of reinvention, Social Choice and Welfare 25, 485-506.

Florence, P. S. [1961] Ownership, Control and Success of Large Companies: An Analysis of English Industrial Structure and Policy, 1936-1951, UK: Sweet \& Maxwell.

Gambarelli, G. [1982] Portfolio selection and firms' control, Finance 3, 69-83.

Gambarelli, G. [1983] Common behaviour of power indices, International Journal of Game Theory 12, 237-244.

Gambarelli, G. [1994] Power indices for political and financial decision making, Annals of Operations Research 51, 165-173.

Gambarelli, G. [1996] Takeover algorithms, in: Bertocchi, M. et al., editors, Modelling Techniques for Financial Markets and Bank Management, Heidelberg: Physica Verlag, pp. 212-222.

Gambarelli, G. and Owen, G. [1994] Indirect control of corporations, International Journal of Game Theory 23, 287-302.

Gambarelli, G. and Pesce, S. [2004] Takeover prices and portfolio theory, Theory and Decision 36, 193-203.

Gorton, G. and Schmid, F. A. [2000b] Universal banking and the performance of German firms, Journal of Financial Economics 58, 29-80.

Grabisch, M. and Rusinowska, A. [2010] Different approaches to influence based on social networks and simple games, in: van Deemen, A. and Rusinowska, A., editors, Collective Decision Making, Berlin, Heidelberg: Springer-Verlag, pp. 185-209.

$\mathrm{Hu}, \mathrm{X}$. and Shapley, L. S. [2003] On authority distributions in organizations: Equilibrium, Games and Economic Behavior 45, 132-152.

Karp, R.M., Luby, M. and Madras, N. [1989] Monte-Carlo approximation algorithms for enumeration problems, Journal of Algorithms 10, 429-448.

Khatri, Y., Leruth, L. and Piesse, J. [2002] Corporate performance and governance in Malaysia, Working paper 152, International Monetary Fund, Washington DC.

Klinz, B. and Woeginger, G. J. [2005] Faster algorithms for computing power indices in 
weighted voting games, Mathematical Social Sciences 49, 111-116.

La Porta, R., Lopez-De-Silanes, F. and Shleifer, A. [1999] Corporate ownership around the world, Journal of Finance 54, 471-517.

Leech, D. [1987a] Corporate ownership and control: A new look at the evidence of Berle and Means, Oxford Economic Papers 39, 534-51.

Leech, D. [1987b] Ownership concentration and the theory of the firm: A simple-gametheoretic approach, Journal of Industrial Economics 35, 225-240.

Leech, D. [1988] The relationship between shareholding concentration and shareholder voting power in British companies: A study of the application of power indices for simple games, Management Science 34, 509-527.

Leech, D. [2002] An empirical comparison of the performance of classical power indices, Political Studies 50, 1-22.

Leech, D. [2003] Computing power indices for large voting games, Management Science 49, 831-838.

Leech, D. and Leahy, J. [1991] Ownership structure, control type classification and the performance of large British companies, Economic Journal 101, 1418-1437.

Leech, D. and Manjòn, M. C. [2003] Corporate governance and game theoretic analyses of shareholder power: The case of Spain, Applied Economics 35, 847-858.

Levy, M. [2009] Control in pyramidal structures, Corporate Governance: An International Review 17, 77-89.

Levy, M. [2011] The Banzhaf index in complete and incomplete shareholding structures: A new algorithm, European Journal of Operational Research 215, 411-421.

Mann, I. and Shapley, L. S. [1960] Values of large games IV: Evaluating the Electoral College by Monte Carlo techniques, Memo RM-2651, The Rand Corporation, Santa Monica, CA.

Matsui, T. and Matsui, Y. [2000] A survey of algorithms for calculating power indices of weighted majority games, Journal of the Operations Research Society of Japan 43, $71-86$.

Megiddo, N. [1974] Nucleolus of compound simple games, SIAM Journal on Applied Mathematics 26, 607-621.

Milnor, J. W. and Shapley, L. S. [1978] Values of large games II: Oceanic games, Mathematics of Operations Research 3,1-9.

Montero, M. [2005] On the nucleolus as a power index, Homo Oeconomicus 4, 551-567.

Nenova, T. [2003] The value of corporate voting rights and control: A cross-country analysis, Journal of Financial Economics 68, 325-351.

Nicodano, G. and Sembenelli, A. [2004] Private benefits, block transaction premiums and ownership structure, International Review of Financial Analysis 13, 227-244.

Owen, G. [1972] Multilinear extensions of games, Management Science 18, 64-79.

Owen, G. [1975] Multilinear extensions and the Banzhaf value, Naval Research Logistics Quarterly 22, 741-750.

Owen, G. [1978] Characterization of the Banzhaf-Coleman index, SIAM Journal of Applied Mathematics 35, 315-327.

Owen, G. [1995] Game Theory, San Diego: Academic Press.

Penrose, L. S. [1946] The elementary statistics of majority voting, Journal of the Royal Statistical Society 109, 53-57.

Pohjola, M. (1988). Concentration of shareholder voting power in Finnish industrial companies, Scandinavian Journal of Economics 90, 245-253.

Rydqvist, K. [1987] The Pricing of Shares with Different Voting Power and the Theory of Oceanic Games, Doctoral Dissertation, Stockholm School of Economics.

Shapiro, N. Z. and Shapley, L. S. [1978] Values of large games I: A limit theorem, Mathe- 
October 9, 2011 18:38 WSPC/INSTRUCTION FILE SurveyCorporateControl

matics of Operations Research 3, 290-307.

Shapley, L.S. [1962] Simple games: An outline of the descriptive theory, Behavioral Science 7, 59-66.

Shapley, L. S. and Shubik, M. [1954] A method for evaluating the distribution of power in a committee system, American Political Science Review 48, 787-792.

Shleifer, A. and Vishny, R. W. [1997] A survey of corporate governance, Journal of Finance 52, 737-783.

Wang, S. [2009] Control and power in corporate and bank networks, Internship report, Paris: Ecole Polytechnique and International Monetary Fund.

Zingales, L. [1994] The value of the voting right - A study of the Milan Stock Exchange experience, Review of Financial Studies 7, 125-148.

Zwiebel, J. [1995] Block investment and partial benefits of corporate control, Review of Economic Studies 62, 161-185. 